\title{
Análise dos Periódicos Brasileiros de Contabilidade
}

\author{
Marcelle Colares Oliveira \\ Professora Adjunta da Universidade Federal do Ceará
}

RESUMO

Esta pesquisa teve como objetivo analisar as características dos Periódicos Brasileiros de Contabilidade. $O$ levantamento das características dessas publicações revelou que a observação das normas, internacionalmente reconhecidas, para a apresentação de periódicos, de fascículos e de artigos, ainda é incipiente. Do levantamento das características dos artigos publicados, no período de 1990 a 1999, em cinco periódicos nacionais de Contabilidade intencionalmente selecionados, observou-se que a maioria dos autores são docentes, evidenciando que ainda é nas universidades que se origina a maioria das pesquisas contábeis, reflexo da carência de centros de pesquisa contábil, dos mecanismos de incentivo à pesquisa e da pressão pela divulgação delas nas Instituições de Ensino Superior. Considerou-se que, como os autores com pós-graduação são a maioria, isso reforça a importância desses veículos de comunicação e de seu conteúdo para a comunidade científica nacional. As cinco áreas temáticas privilegiadas com maior percentual de trabalhos são, sucessivamente, Contabilidade Gerencial, Contabilidade Financeira, Teoria da Contabilidade, Educação e Pesquisa Contábil e Contabilidade de Custos. Os temas mais abordados nos periódicos evidenciam uma mudança no paradigma contábil, realçando a importância da Contabilidade Gerencial e das pesquisas sobre esse tema, bem como o interesse dos pesquisadores sobre os assuntos a ele relacionados. Entretanto percebeu-se que temas atuais e importantes, como Contabilidade Internacional, Contabilidade e Mercado de Capitais e Contabilidade Social e Ambiental, ainda carecem de pesquisas. Em suma, produzir artigos e periódicos de melhor qualidade constitui um desafio para os cientistas contábeis brasileiros neste milênio.

Palavras-chave: periódicos brasileiros de contabilidade; pesquisa contábil, paradigma contábil.
ABSTRACT

The objective of this research was to analyze the characteristics of Brazilian accounting periodicals and the articles published in them. Our analysis revealed that, in the Brazilian accounting periodicals, the observation of internationally recognized standards for the presentation of periodicals, quires and articles is still in its initial stage. The survey of the articles published between 1990 and 1999 in five Brazilian accounting periodicals that were selected on purpose revealed that most of the authors are lecturers, which demonstrates that the universities still originate most of the accounting research. The fact that most of the authors have a post-graduate degree was considered a strengthening factor of the importance of these communication vehicles and their contents for the national scientific community. The five thematic areas with the highest number of works are, successively, Management Accounting, Financial Accounting, Accounting Theory, Accounting Education and Research and Cost Accounting. The main themes dealt with in the periodicals demonstrate a change in the accounting paradigm, emphasizing the importance of Management Accounting and research on this theme, as well as the researchers' interest in subjects related to it. However, it was perceived that there is still a lack of research in current and important themes such as International Accounting, Capital Market Accounting and Social and Environmental Accounting. In summary, the production of higher-quality accounting research and periodicals constitutes a challenge to Brazilian accounting scientists for this millennium.

Keywords: Brazilian accounting periodicals, accounting research, accounting paradigm. 


\section{INTRODUÇÃO}

A comunicação é elemento indispensável para a atividade científica, uma vez que, sem ela, não existiria ciência e não se poderiam somar os esforços individuais dos membros das comunidades científicas.

Segundo REY (1978, p.4), "A produção de informações científicas e sua comunicação fazem parte de um sistema complexo, cujo funcionamento é essencial ao desenvolvimento do conhecimento científico."

A comunicação científica, entendida como o conjunto de atividades associadas à disseminação e ao uso da informação, é importante para a aceitação do que é produzido cientificamente como constituinte do conhecimento científico.

Os meios formais, pelos quais se processa a comunicação científica, em sua versão primária, abrangem periódicos, teses, dissertações, relatórios, anais e atas de congressos, patentes.

Os periódicos têm um papel importante no fomento da qualidade da pesquisa e para o avanço do conhecimento, mediante seleção e divulgação dos trabalhos.

Os artigos publicados em periódicos representam uma relevante parte do fluxo de informação originado com a atividade científica de pesquisa.

A produção científica, divulgada em forma de artigos publicados em periódicos, é importante sob vários aspectos:

- os artigos podem ser colecionados, classificados, catalogados e reproduzidos infinitamente;

- os cientistas não publicam livros nem defendem teses e dissertações com freqüência, além do que a agilidade na circulação destes veículos e, conseqüentemente, da informação contida neles, principalmente quando se trata de teses e dissertações, é mais lenta;

- os artigos de periódicos atingem mais velozmente que teses e dissertações um público maior, servem como fonte de bibliografia e contribuem para a atualização dos que os lêem.
Além disso, como os cientistas em todo o mundo via de regra são avaliados pela sua contribuição para a ciência através de sua produção científica, os artigos e os periódicos têm um grande peso nesta avaliação, uma vez que estão entre os principais instrumentos e veículos de divulgação da produção científica.

Ao passo que a utilização do critério quantitativo de avaliação dos cientistas impulsiona o aumento do número de artigos científicos e o surgimento de novos periódicos, ela também pressupõe a necessidade da existência de um conhecimento organizado sobre esses artigos e periódicos.

Assim, a utilização desse critério também tem impulsionado o movimento no sentido de se mapearem e se avaliarem os periódicos técnicos e científicos nas diversas ciências, com o intuito de contribuir para o desenvolvimento da qualidade dos trabalhos neles publicados e para a disseminação das informações neles contidas.

Em pesquisa realizada por $Z_{E F F}{ }^{1}$, em 1988, o autor verificou a existência de 42 periódicos científicos internacionais de contabilidade publicados nos Estados Unidos.

Posteriormente, ZEFF (1996) realizou pesquisa semelhante à anterior, em que identificou 77 periódicos científicos de contabilidade editados em Inglês, investigou as razões para o surgimento de novos periódicos e examinou a situação referente à distribuição dos periódicos pelas livrarias e à inclusão deles em catálogos impressos e em bancos de dados eletrônicos.

As principais constatações de ZEFF (1996) são mencionadas a seguir:

- na contabilidade, ocorre o mesmo crescimento acelerado no número de periódicos que se verifica em outros campos;

- a falta de periódicos de alto prestígio que abranjam todas as áreas temáticas e métodos de pesquisa é apontada como uma das causas desse crescimento na área contábil nos Estados Unidos, impulsionando o aparecimento de periódicos que privilegiam áreas e metodologias específicas (como os que somente publi- 
cam artigos de auditoria, contabilidade gerencial, e os que privilegiam artigos que utilizam determinados métodos de pesquisa);

- tal crescimento tem como conseqüência maior demanda por referees (pareceristas); entretanto, o número de referees não aumenta proporcionalmente ao aumento no número de periódicos, mas cresce o número de periódicos aos quais os mesmos referees estão vinculados;

- outra conseqüência é que, como as livrarias, em virtude de seus limitados orçamentos, têm dificuldade de acompanhar esse crescimento em termos de se subscreverem para distribuírem-nos, parte desses periódicos não são conhecidos pela comunidade científica, não sendo recebidos por muitas delas; pior ainda é a ausência desses periódicos nos catálogos impressos e bancos de dados eletrônicos, o que resulta na obscuridade dos artigos publicados neles.

Nem sempre o autor de um trabalho científico se interessa pela maneira como se opera a circulação das informações que publica. Em verdade, costuma ter sobre ela uma idéia simplista, dando-se por satisfeito quando vê seu trabalho impresso em uma revista.

Entretanto, o cientista não deve ficar alheio à participação que os resultados de sua investigação possa ter tido no avanço das áreas vinculadas à sua ciência. Qualquer informação científica é vã se não chegar a ser utilizada por outros cientistas nas etapas subseqüentes de determinada investigação, ou se não for aproveitada pelas pessoas que promovem sua aplicação prática.

Por esses motivos e primando pela qualidade dos artigos é que não basta apenas publicar, mas publicar em periódicos comprometidos com o seu papel de fomento da qualidade dos artigos e disseminação das informações.

Segundo SCHWARTZMAN (1984, p.25),

"Publicações científicas e técnicas, quando feitas em revistas de boa qualidade, dotadas de sistemas adequados de avaliação e crítica de manuscritos, desempenham ainda duas funções primordiais, ainda que pouco evidentes à primeira vista. Primeiro, elas têm um importante papel pedagógico junto ao pesquisador, que é levado a expor o resultado de sua pesquisa a outros especialistas em seu campo, recebendo sugestões, críticas e comentários que podem ser decisivos para aperfeiçoar e mesmo reorientar os trabalhos. Segundo, os corpos editoriais das revistas funcionam como um mecanismo altamente qualificado de avaliação final da pesquisa."

Segundo ZEFF (1996, p. 160), nos Estados Unidos a sobrevivência dos cientistas em suas faculdades ou universidades é determinada pela sua produtividade científica, com ênfase na publicação em periódicos de alto prestígio, que é uma tentativa de conciliar quantidade com qualidade.

Uma conseqüência disso são as freqüentes pesquisas realizadas nesse país para estabelecer listas de periódicos científicos internacionais e arbitrados, bem como ranking de periódicos.

Pode-se citar como exemplo disso a pesquisa de BENJAMIN \& BRENNER (1974) para estabelecer um ranking dos periódicos, tendo em vista, segundo os autores, o fato de o prestígio do periódico ser um aspecto decisivo na pontuação da produção, ou seja, um docente pode obter mais ou menos pontos conforme os periódicos em que seus artigos apareçam; HOWARD \& NIKOLAI (1983) também realizaram pesquisa para estabelecer um ranking dos periódicos publicados por faculdades de contabilidade dos Estados Unidos; e HULL \& WRIGHT (1990) realizaram pesquisa que consistia em uma atualização da investigação anterior.

Segundo esses autores, na análise da contribuição de um artigo para a comunidade científica e para o avanço da ciência, são muito prestigiados nesse país os periódicos que privilegiam a originalidade e a atualidade dos temas abordados; um exemplo disso é a menção desses aspectos entre os critérios para seleção dos artigos pela maioria dos periódicos.

Os trabalhos que procuram realizar uma análise crítica da produção científica contábil veiculada em periódicos, do ponto de vista de métodos de pesquisa utilizados e temas abordados, são uma conseqüência da importância atribuída aos métodos e temas para o avanço das ciências. 
PRATHER E RUESCHHOFF (1996) realizaram estudo das pesquisas sobre contabilidade internacional divulgadas nos Periódicos Acadêmicos de Contabilidade dos Estados Unidos arbitrados, analisando o número e a qualidade dos artigos e cobrindo os métodos de pesquisa usados, além de outros aspectos.

FELIU \& GOMES (1998) realizaram um estudo sobre a investigação na área de Contabilidade Gerencial, no Brasil e na Espanha, através de artigos publicados em periódicos ligados à Ciência Contábil desses países, no período de 1991 a 1996, buscando chamar a atenção para o estado-da-arte das pesquisas nessa área nesses países.

RICCIO, SAKATA e SEGURA (1999) realizaram estudo acerca da pesquisa sobre custos no Brasil, com o objetivo de analisar e demonstrar a composição e a evolução temática dos trabalhos científicos de custos apresentados no período de 1967 a 1999, e contribuir para o estudo e a compreensão das tendências das pesquisas nessa área.

Em pesquisa realizada por FELIU E PALANCA (2000), sobre a tendência atual da Contabilidade Gerencial, os autores utilizaram a teoria de BUNGE(2) para análise do desenvolvimento científico e da natureza e tipologia da pesquisa em uma ciência social e analisaram 261 artigos, escritos entre os anos de 1972 e 1996, selecionados em 13 periódicos considerados importantes na área de gestão.

BORBA \& FREZATTI (2000), visando a despertar o interesse de cientistas brasileiros em publicar suas pesquisas em revistas internacionais, bem como auxiliá-los na escolha desses veículos, realizaram um estudo sobre uma amostra das revistas científicas da área de contabilidade publicadas em Língua Inglesa. Foram investigadas características como freqüência de publicação, utilização de métodos quantitativos (pouca ou nenhuma, razoável ou sofisticada), tipos de enfoques (empírico, teórico, teórico-empírico, profissional) e áreas predominantes (Contabilidade Gerencial e Custos, Auditoria, Contabilidade e Mercado Financeiro, Contabilidade Geral, Contabilidade Internacional, Fiscal e Impostos, Educação, Tecnologia e Sistemas e, finalmente, Ética).

Também são aspectos internacionalmente considerados importantes para reforçar o prestígio de um periódico sua indexação, a titulação e a abrangência na origem dos membros do corpo edi- torial e dos autores, pois esses aspectos depõem sobre a imparcialidade e a autoridade na seleção dos trabalhos e aqueles sobre a circulação das informações.

Segundo KRZYZANOWSKI \& FERREIRA (1998, p. 166), "a partir da década de 60 , encontram-se na literatura estudos sobre avaliação de revistas científicas e técnicas que demonstram a necessidade de se definir parâmetros mensuráveis, que possam refletir a qualidade da informação registrada."

A idéia desenvolvida nesses estudos é a de que as características formais de apresentação, composição e divulgação dos periódicos são parâmetros que podem influir na sua aceitabilidade pelas comunidades nacional e internacional, bem como no padrão de qualidade do conteúdo dos artigos.

Os periódicos técnicos e científicos têm sido objeto de estudo em diversos países e têm sofrido críticas quanto ao desempenho de seu papel no fomento à qualidade e na disseminação das pesquisas, dentre as quais podem-se destacar, segundo KRZYZANOWSKI \& FERREIRA (1998; p.165):

\section{“ • irregularidade na publicação e distribui- ção da revista;}

- falta de normalização dos artigos científicos e da revista como um todo;

- falta do corpo editorial e de referees (autoridade da revista).

No panorama nacional, acrescem-se os seguintes aspectos:

- pouca penetração da língua portuguesa no exterior;

- baixo grau de originalidade e novidade dos artigos científicos publicados."

Dada a importância dos periódicos para a comunicação científica e para a avaliação dos cientistas e dada a quase inexistência de pesquisas no Brasil sobre os periódicos nacionais de contabilidade, acredita-se que conhecê-los em maior profundidade contribuirá para apontar os pontos fortes e os fracos e para melhorá-los.

Este trabalho propõe uma análise dos periódicos brasileiros de contabilidade e baseia-se no modelo para avaliação de periódicos científicos utilizado pela Fundação de Amparo à Pesquisa do Estado de São Paulo - FAPESP, com o objetivo de subsidiar os progra- 
mas de apoio a publicações científicas da própria Fapesp, do Conselho Nacional de Desenvolvimento Científico e Tecnológico - CNPq e da Financiadora de Estudos e Projetos - Finep, adaptando-o às especificidades da Ciência Contábil no Brasil.

O estudo do estado-da-arte dos periódicos brasileiros especializados em contabilidade é muito importante, uma vez que eles estão entre os principais instrumentos de divulgação da produção científica contábil.

Este estudo é relevante também porque é compatível com a realidade e o momento de publicação científica no Brasil, em que a discussão sobre as características dos periódicos nas diversas ciências tem estado em foco.

Chama-se a atenção para o fato de não se ter em vista uma avaliação da qualidade dos periódicos, mas mapear o universo das publicações seriadas sobre contabilidade produzidas no Brasil, analisando suas características para que se possa ter uma visão crítica das publicações.

Busca-se também apresentar sugestões visando à melhoria dos periódicos como uma maneira de se caminhar no sentido de que periódicos produzidos com maior rigor impliquem a oferta de artigos melhor produzidos.

Os trabalhos sobre periódicos refletem a preocupação com o assunto, podendo-se dizer que a discussão é principalmente centrada em dois pontos:

a) nos métodos utilizados nas pesquisas que originaram os artigos e nos temas enfocados nestes;

b) nas características dos periódicos que reforçam a qualidade dos artigos neles publicados.

Esses trabalhos pretendem, ao enfocar esses dois pontos, mostrar que a contribuição dos artigos publicados para o avanço da ciência pode ser garantida de duas maneiras: ou eles já tiveram origem em pesquisas que utilizaram métodos ou abordaram temas originais, ou isso pode ser assegurado por uma criteriosa seleção dos artigos por parte dos corpos editoriais dos periódicos, o que implica que os periódicos devem apresentar características que assegurem a qualidade dos trabalhos publicados e a sua disseminação.

Análise significa o exame de cada parte de um todo. A análise dos periódicos brasileiros de contabilidade ora proposta abrange:
- a verificação das características formais desses periódicos;

- a investigação das características dos artigos publicados, como temas abordados e autoria (titulação e ocupação dos autores, instituição a que se vinculam, origem geográfica).

Acredita-se que essa análise será decisiva para a melhoria dessas publicações e auxiliará no processo de orientação de cientistas, objetivando a oferta de trabalhos de significância superior aos até então produzidos.

As características dos periódicos nacionais de contabilidade e dos artigos neles publicados são o objeto deste estudo. Portanto, serão estudadas as características dos artigos relativas à autoria e aos temas abordados, bem como as características dos periódicos que asseguram a qualidade e a divulgação dos trabalhos.

Não há, entretanto, pretensão de julgar a qualidade das pesquisas, o mérito da abordagem ou a técnica de pesquisa escolhida pelos autores.

Como a avaliação da contribuição dos cientistas para o avanço das ciências centra-se, principalmente, na quantidade publicada, não havendo muito controle da qualidade dos periódicos e, por conseguinte, dos artigos, as discussões a respeito da avaliação quantitativa dos cientistas e das características dos periódicos que reforçam a sua qualidade têm se intensificado nas comunidades científicas de todo o mundo.

Isso torna o momento propício para se realizar uma reflexão sobre os periódicos nacionais especializados em contabilidade.

A pouca literatura sobre o estado-da-arte dessas publicações no país conduziu aos seguintes questionamentos:

- Quais as características relativas à forma dos periódicos nacionais especializados em contabilidade?

- Quais as características relativas aos temas e à autoria dos artigos publicados nesses periódicos?

Em função desses questionamentos, constituem objetivos do estudo:

- Mapear o universo das publicações periódicas produzidas no país e elaborar um Catálogo dos Periódicos Brasileiros Especializados em Contabilidade que veiculam a produção científica contábil nacional; 
- Descrever e analisar as características desses periódicos relativas à forma;

- Identificar e analisar as características relativas aos temas e à autoria dos artigos publicados nesses periódicos.

METODOLOGIA

Em função dos objetivos do estudo, adotou-se uma abordagem empírico-teórica, realizando-se pesquisa bibliográfica e documental e utilizando-se as técnicas de Análise de Conteúdo.

A natureza da pesquisa impôs atividades exploratórias de levantamento, sistematização e análise dos seguintes dados secundários:

- periódicos nacionais especializados em contabilidade com publicação em andamento;

- características desses periódicos;

- características dos artigos desses periódicos.

Inicialmente, foi feito um levantamento dos periódicos de contabilidade produzidos no Brasil, disponíveis nas bibliotecas de órgãos de classe e nas bibliotecas das universidades com programas de pós-graduação em contabilidade autorizados pela CAPES.

Esse levantamento foi complementado com consulta ao Catálogo Coletivo Nacional - CCN editado pelo Instituto Brasileiro de Informação em Ciência e Tecnologia/ Ministério da Ciência e
Tecnologia (IBICT/MCT) e com informações obtidas com a ajuda do Conselho Federal de Contabilidade - CFC, através de ofício expedido aos Chefes de Departamentos ou Coordenadores de Cursos de Ciências Contábeis das universidades do país, bem como visitas a universidades, consultas a bibliotecas e contatos mantidos com professores e profissionais de contabilidade, via internet.

Após um levantamento inicial dos títulos, por tratar-se de um universo bastante fluido, e tendo em vista os objetivos do presente estudo, foram selecionados para análise somente os periódicos em que se publicava, entre outras matérias, a produção dos cientistas contábeis: as revistas produzidas por institutos de pesquisas, por cursos de Ciências Contábeis de Instituições de Ensino Superior, públicas ou privadas, ou a eles vinculadas e por órgãos ou associações da classe contábil.

Não foram considerados os boletins informativos e jornais produzidos por órgãos e associações da classe contábil, quando não se tratava de publicações periódicas e somente eventualmente apresentavam informações que contribuíam para a disseminação do saber científico.

Em função da diversidade, os periódicos selecionados foram classificados segundo a classificação adaptada da pesquisa de ORTEGA, FÁVERO \& GARCIA (1998), como segue:

\section{QUADRO 1}

\section{CLASSIFICAÇÃO DOS PERIÓDICOS CORRENTES DE CONTABILIDADE}

\begin{tabular}{|c|c|}
\hline CLASSIFICAÇÃO & CARACTERÍSTICAS \\
\hline $\begin{array}{l}\text { PERIÓDICOS CIENTÍFICOS, } \\
\text { que, segundo a temática e a circu- } \\
\text { lação, desdobram-se em: } \\
\text { Científico Geral } \\
\text { Científico Especializado }\end{array}$ & $\begin{array}{l}\text { Publicações periódicas, direta ou indiretamente vinculadas a instituições de ensino ou a centros de } \\
\text { pesquisa em contabilidade. } \\
\text { Veiculação do conhecimento gerado nessas instituições e nesses centros. } \\
\text { Compreendem temáticas variadas, normalmente editados por faculdades, centros de pesquisa ou } \\
\text { associações científicas. } \\
\text { Publicações vinculadas a uma única temática contábil ou recortes da atividade contábil (p. e.: } \\
\text { auditoria, controladoria, gestão de custos). }\end{array}$ \\
\hline $\begin{array}{l}\text { PERIÓDICOS GENÉRICOS, que, } \\
\text { segundo a produção e a circulação } \\
\text { de informações, desdobram-se em: }\end{array}$ & $\begin{array}{l}\text { São veículos próprios de organizações não-governamentais e associações profissionais. } \\
\text { Abordam questões gerais de contabilidade em função dos objetivos que regem sua proposta editorial. } \\
\text { Aqueles que, tendo a contabilidade como sua temática determinante e optando por uma abordagem } \\
\text { genérica, interessam a muitos. } \\
\text { Publicam conteúdo variado, dividido ou não em seções, como artigos, entrevistas e depoimentos. } \\
\text { No geral, são conhecidos, direta ou indiretamente, por grande número de profissionais da área ou } \\
\text { que com esta mantém relação próxima. } \\
\text { Destinam-se a um público amplo e possuem um grande número de assinantes. } \\
\text { Normalmente editados por sindicatos, associações, fundações, visando a seus associados e } \\
\text { funcionários. }\end{array}$ \\
\hline
\end{tabular}


A análise das características dos periódicos brasileiros especializados em contabilidade foi orientada pelo modelo proposto por KRZYZANOWSKI \& FERREIRA (1998), para avaliação de periódicos científicos nacionais, cujas dimensões são mencionadas a seguir.

Conforme o referido modelo, para se avaliar um periódico, devem ser contemplados os seguintes tópicos: normalização do periódico no todo, do fascículo e dos artigos; indicação de periodicidade e instruções aos autores; e apresentação da filiação e titulação dos autores.

A normalização da forma dos periódicos, dos fascículos e dos artigos se refere à observação de normas que ordenam uma atividade específica. No Brasil, via de regra, são utilizadas como parâmetro as normas da Associação Brasileira de Normas Técnicas - ABNT. A obediência a essas normas depõe sobre a qualidade da publicação.

No tocante às publicações periódicas, a ABNT possui normas sobre, por exemplo, a utilização da numeração internacional para publicações seriadas - ISSN; legendas bibliográficas, sumário do fascículo, resumos e referências bibliográficas.

$\mathrm{Na}$ avaliação de periódicos, segundo o modelo citado, devem ser considerados ainda tópicos como origem e titulação do corpo editorial e dos consultores, abrangência quanto à origem dos trabalhos, natureza do órgão publicador, abrangência quanto à difusão da revista e indexação.

Para a análise das características de cada periódico, foi considerado o último exemplar de 1999 (e, além deste, quando disponíveis, o número imediatamente anterior e o posterior) e foram feitas anotações em fichas individuais, adaptadas do modelo citado, elaboradas para esse fim, contemplando tópicos considerados imprescindíveis para se analisar um periódico.

No tocante aos artigos, para que um trabalho contribua para a evolução do saber em determinada ciência, os estudos apontam como características importantes, via de regra, a originalidade e a oportunidade dos temas abordados. Esta pesquisa contou com análise documental envolvendo os seguintes procedimentos:

- classificação temática dos artigos; e

- identificação de aspectos referentes à origem dos trabalhos, como filiação, titulação e ocupação dos autores.
Foram selecionados cinco periódicos nacionais e pesquisadas as características dos artigos publicados nos dez últimos anos (1990-1999), acerca dos temas abordados, da filiação, da titulação e da ocupação dos autores.

Os periódicos utilizados nessa parte do estudo foram selecionados segundo os seguintes critérios: - antiguidade - periódicos que publicam há mais tempo; $\mathbf{e}$

- representatividade dos órgãos e instituições produtores desses periódicos, para os profissionais e cientistas da área.

Esta parte do estudo está, pois, demarcada por duas delimitações: primeiro, refere-se somente a cinco periódicos, eleitos pelos critérios acima descritos; segundo, conforma-se com um período de tempo de dez anos (1990-1999).

Essa delimitação temporal socorreu-se do pressuposto de que se pode inferir com mais segurança sobre a evolução temática partindo do exame de uma situação temporal mais longa, do que partindo da consideração de condições que prevaleceram num período mais curto.

Para o levantamento dos temas dos artigos, foi necessário eleger um critério classificatório das áreas do conhecimento contábil. Foi utilizada uma classificação adaptada de outras classificações, em que foram elencadas 17 áreas temáticas, e os assuntos associados a cada uma delas foram detalhados.

Para a análise dos temas e dos aspectos referentes à origem dos artigos de cada fascículo, foram feitas anotações em ficha elaborada para este fim; as informações foram sintetizadas em fichas contendo um roteiro complementar para análise do conteúdo de cada periódico.

\section{ANÁLISE DOS PERIÓDICOS NACIONAIS DE CONTABILIDADE}

A pesquisa se concentra em estudar as características dos artigos científicos publicados em periódicos nacionais de contabilidade, bem como as características desses periódicos que asseguram a qualidade e a disseminação dos trabalhos.

Admitindo-se que as características formais desses meios de comunicação são decisivas para sua aceitabilidade pela comunidade nacional e interna- 
cional e são indicadoras da qualidade dos artigos selecionados para divulgação, buscou-se, inicialmente, mapear o universo desses periódicos e descrever e analisar aspectos do conteúdo e da forma, para que se pudesse ter uma visão crítica dessas publicações e passar ao estudo dos artigos.

O resultado dessa parte da pesquisa é uma proposta de Catálogo dos Periódicos Brasileiros de Contabilidade que divulgam a produção científica contábil nacional, e a análise crítica das características formais desses periódicos. Esse catálogo apresenta 15 títulos que se encontram em andamento e que serão objeto da análise a seguir.

Esse reduzido número de periódicos nacionais de Contabilidade é condizente com as condições existentes no país para o desenvolvimento de pesquisas contábeis: pequeno número de Instituições de Ensino Superior - IES - comprometidas com o desenvolvimento e a divulgação de pesquisas; pequeno número de centros ou institutos de pesquisa nessa área do conhecimento; pequeno número de cursos de pós-graduação stricto sensu em Contabilidade e, conseqüentemente, reduzido número de cientistas contábeis aptos a realizarem pesquisas.

A maioria dos periódicos é produzida por IES e os que são produzidos por Centros ou Institutos de Pesquisas e Sociedades Científicas estão direta ou indiretamente ligados a IES. Os produzidos por um ou outro tipo de instituição são periódicos científicos, e no total são a maioria dos periódicos.

Ao crescimento no número de cursos de pósgraduação lato sensu em Contabilidade, oferecidos pelas IES, associou-se o surgimento de pesquisas contábeis nessas instituições, sendo as revistas uma maneira encontrada para divulgá-las. Também associou-se o surgimento dessas revistas, nas IES, à criação de novos cursos de pós-graduação stricto sensu em contabilidade.

Além de as disciplinas e os assuntos discutidos servirem de estímulo à realização de pesquisas, a produção científica de docentes e discentes é um dos parâmetros praticados pela CAPES para que os cursos sejam recomendados por essa instituição, o que torna quase obrigatória a divulgação das pesquisas, justificando a produção das revistas.

Até 1988, existiam no país apenas três periódicos de Contabilidade, todos genéricos, segundo a classificação adotada nessa pesquisa, ou seja, não havia periódicos científicos. Entre outros assuntos, eles publicavam artigos científicos. Esses periódicos eram vinculados a órgãos de classe e, apesar de serem bastante antigos, somente a Revista Brasileira de Contabilidade possuía uma maior abrangência quanto à origem do trabalho e à difusão da revista.

Em 1989 e 1990, surgiram os primeiros periódicos científicos. Todos ainda muito rudimentares: abrangência restrita, quanto à origem dos trabalhos e à difusão da revista, quase que exclusivamente a indivíduos vinculados à instituição produtora; ausência de corpo editorial permanente e referees; ausência de rigidez na periodicidade; e não-padronização do formato do periódico, dos artigos e das referências bibliográficas.

O surgimento da maioria dos periódicos nacionais de Contabilidade ocorreu a partir do início dos anos 90, o que pode ser explicado, em parte, pelo fato de os periódicos mais antigos, mais gerais e de divulgação mais abrangente não estarem comportando a produção científica originada com a crescente oferta de cursos de pós-graduação lato sensu em Contabilidade vivida no país, e com os egressos dos cursos de pós-graduação stricto sensu. Além disso, essa produção aumentou devido, entre outras coisas, à pressão provocada pelos mecanismos de avaliação da CAPES e das Instituições Federais de Ensino Superior para a divulgação da produção docente e discente.

Embora esses fatos expliquem a criação de novos periódicos, a dificuldade de seu acesso e de sua localização em bibliotecas, às vezes até da própria instituição ou de instituições da região onde são produzidos, provoca uma fragmentação da produção científica veiculada nos periódicos brasileiros de Contabilidade.

\section{Análise do Corpo Editorial}

São internacionalmente considerados um indicador da qualidade necessária ao julgamento abalizado e imparcial dos trabalhos os corpos editoriais formados por cientistas com elevada titulação acadêmica ou profissionais com reconhecida competência nos meios acadêmicos, bem como com diversas origens institucionais, regionais e nacionais, uma vez que isso garante a diversidade de 
opiniões sobre temas e metodologias, o que influi na qualidade dos trabalhos selecionados para publicação, bem como na oferta de trabalhos mais significativos.

A análise do corpo editorial dos periódicos com publicação em andamento percorreu três caminhos: primeiro, averiguaram-se quais periódicos divulgam essa informação; segundo, verificou-se se apresentam a qualificação de seus membros (origem e titulação); finalmente, buscaram-se a origem e a titulação desses membros.

Nem todos os periódicos indicam os nomes dos membros do conselho editorial, mas todos mencionam a submissão dos trabalhos à avaliação por esses indivíduos. Dos quinze periódicos analisados, um não divulga sequer os nomes dos membros do conselho editorial e apenas três o fazem de maneira completa, indicando a origem institucional e a titulação desses indivíduos. Dos onze periódicos restantes, seis não divulgam a origem nem a titulação dos membros do corpo editorial, mas apenas seus nomes; três divulgam somente a origem e dois somente a titulação desses indivíduos.

Tudo isso revela amadorismo na produção dos periódicos, uma vez que essas informações depõem sobre a autoridade e a imparcialidade no julgamento dos trabalhos, sendo sua divulgação de suma importância, e não apenas uma ilustração.

Dada a inadequada divulgação da informação sobre os membros do conselho editorial pela maioria dos periódicos analisados, foram mantidos contatos telefônicos com os responsáveis pelos periódicos ou pessoas que por eles respondessem, para a identificação da origem e da titulação desses indivíduos.

Percebeu-se que sete dos quinze periódicos analisados possuem seu conselho editorial composto apenas por cientistas e profissionais vinculados à instituição produtora (46,66\%). Isso é um aspecto negativo para esses periódicos, porque atesta a falta de interação dos editores e da instituição com membros de outras comunidades científicas.

Outro aspecto negativo é que isso naturalmente se reflete no controle de qualidade dos artigos submetidos à publicação - o que se agrava quando considerada a escassez de material para publicar -, assim como compromete a credibilidade na imparcialidade do julgamento dos trabalhos escritos por outros membros da comunidade institucional.

Os periódicos com conselhos editoriais mesclados por indivíduos vinculados a outras instituições, além da produtora, estão assim distribuídos: seis deles possuem membros de comunidades científicas de várias regiões do país (40,00\%), sendo que dois desses possuem membros estrangeiros; um possui apenas membros da comunidade científica regional $(6,67 \%)$; um possui apenas membros da comunidade científica estadual (6,67\%).

É importante a participação de membros estrangeiros, demonstrando contatos mantidos não só pelos editores do periódico, mas também pela instituição que o produz. Evidentemente, a simples listagem de membros estrangeiros não garante a qualidade de uma publicação, se esses profissionais ou cientistas não são solicitados para atuarem como colaboradores efetivos.

Percebeu-se um grande número de periódicos com doutores em seu corpo editorial. Dos quinze periódicos, quatro possuem corpo editorial composto exclusivamente por doutores $(26,67 \%)$; três possuem somente mestres e doutores (20\%); cinco possuem graduados, especialistas, mestres, doutores $(33,33 \%)$ e três possuem somente graduados e especialistas (20\%). Esses dados mostram que os responsáveis pelos periódicos estão atentos para a necessidade de cientistas e profissionais potencialmente qualificados para o julgamento dos trabalhos.

Percebeu-se, também, que, a exemplo do que acontece nos Estados Unidos, segundo ZEFF (1996), principalmente quando se trata de doutores, os cientistas ou profissionais fazem parte do corpo editorial de vários periódicos.

No caso do Brasil, isso poderia ser explicado, em parte, não pela quantidade de periódicos, mas pela escassez de doutores, uma vez que existe apenas um curso de doutorado no país. Por outro lado, pode-se atribuir isso à pequena quantidade de cientistas ou profissionais envolvidos com a atividade de julgamento de trabalhos. De qualquer forma, constitui um aspecto negativo corpos editoriais que contam apenas com cientistas e profissionais vinculados à instituição produtora do periódico e com especialistas ou graduados. 


\section{Análise da Forma de Acesso aos Periódicos e do Alcance da sua Distribuição}

Somente na década de 90 foi incorporada à cultura dos periódicos nacionais de contabilidade a distribuição via assinatura e, timidamente, esta prática está se disseminando, o que possibilita um maior alcance dessa distribuição, além de viabilizar a subsistência e a autonomia financeira, implicando benefícios para a publicação.

Como na Ciência Contábil a produção de periódicos intensificou-se somente a partir de meados dos anos 90, muitas práticas comuns em outras ciências, como a distribuição por meio de assinatura, estão sendo introduzidas recentemente.

Entretanto, a distribuição por meio de assinatura implica um esforço muito grande pelos editores dos periódicos menores, que têm de realizar um marketing muito forte para conseguir assinantes, pois, via de regra, os indivíduos não mantêm recursos para acumular a assinatura de várias revistas, tendo obviamente de fazer uma seleção.

É bastante comprometedora a forma de acesso aos periódicos, uma vez que a maioria deles possui distribuição gratuita e restrita. Essa situação se agrava em virtude da dificuldade de localização deles em bibliotecas. A maioria desses periódicos não consta do acervo da biblioteca de instituições de importante referência para os cientistas e profissionais da área contábil, como USP, PUC/SP, UERJ e UFRJ (precursoras na oferta de cursos de pós-graduação em contabilidade), bem como do Conselho Federal e dos Conselhos Regionais de Contabilidade.

Como já foi comentado, o cientista não pode ficar alheio à forma de circulação dos periódicos, dando-se por satisfeito simplesmente por ter seu artigo publicado, pois a dificuldade de acesso às publicações prejudica a comunicação científica.

Para a verificação da indexação dos títulos em base de dados nacionais e internacionais, foram consideradas as fontes registradas nos periódicos. Para identificar se uma revista é indexada ou não, na parte da apresentação, os editores colocam os indexadores, mais ou menos desta forma: "A revista está indexada em..." Ou os indexadores são simplesmente listados na capa ou contracapa.

Na pesquisa realizada por ZEFF (1996), sobre periódicos de contabilidade publicados em Língua Inglesa, ele se surpreende porque dos 68 journals que surgiram a partir de 1994, apenas cerca de $50 \%$ deles estavam indexados em alguma base de dados. Na Ciência Contábil, no Brasil, nenhum periódico faz menção à indexação, o que respalda a assertiva de que a produção de periódicos nacionais, nessa ciência, é ainda incipiente.

Em outras ciências, como é o caso da Medicina, segundo CASTRO, FERREIRA \& VIDILI (1996), a maioria dos periódicos latino-americanos é indexada em várias bases de dados internacionais.

\section{Análise da Normalização do Periódico}

Os estudos sobre avaliação de periódicos têm reforçado a idéia de que as características formais desses veículos de comunicação são indicativas da sua qualidade e de que elas podem interferir no padrão de qualidade do seu conteúdo e na sua aceitação no processo de seleção de títulos a serem incluídos em bases de dados, principalmente se apresentam características aclamadas internacionalmente.

A legenda bibliográfica deve ser incluída em locais visíveis e, se possível, em mais de um lugar (capa, sumário, nas páginas do texto ou, no mínimo, na página inicial dos artigos). Isso facilita a identificação do periódico em caso de reprodução de artigos. Uma legenda bibliográfica pode ser considerada completa, quando, além do título do periódico, ela informa o volume, o número, o(s) mês(meses), o local e o ano referente ao fascículo. Muitos periódicos costumam repetir, além dessas informações, o título do artigo em todas as suas páginas. Entretanto, uma legenda que possui apenas o título do artigo não pode ser considerada bibliográfica, pois omite informações importantes.

Dois dos cinco periódicos classificados nessa pesquisa como genéricos apresentam legenda bibliográfica completa. Os outros três periódicos genéricos apresentam legenda incompleta. Dos dez periódicos classificados nessa pesquisa como científicos, seis deles apresentam legenda bibliográfica completa em todas as páginas. Dos quatro periódicos científicos restantes, dois não apresentam legenda e os outros dois apresentam legenda incompleta. Do exposto, percebe-se que não é dada a devida atenção a essa característica formal dos periódicos. 
A maioria dos periódicos apresenta o International Standard Serial Number - ISSN (60\%). Em um dos periódicos, o ISSN estava quase imperceptível, dificultando a sua localização, embora seja importante que essa informação apareça em locais visíveis do fascículo. Dada a importância do ISSN, os periódicos deveriam dar mais atenção à sua obtenção, pois a sua existência facilita a identificação do periódico, o intercâmbio, a organização de acervos, o empréstimo interbibliotecas, a aquisição, a indexação.

A periodicidade é uma informação importante para quem pretende mandar artigos para publicação, pois quanto mais freqüente significa que a informação circula com maior agilidade, e também para confirmar a regularidade da revista, que é outro dado essencial para quem pretende publicar artigos, pois atesta sobre a confiabilidade do periódico no tocante à circulação das informações.

Apenas dois dos periódicos pesquisados (13,33\%) não divulgaram a periodicidade. A periodicidade mais freqüente foi encontrada nos dois periódicos genéricos mais antigos (estes bimestrais). Aliás, ressaltese que os periódicos genéricos não apresentam problemas de regularidade na periodicidade. Os demais periódicos genéricos são trimestrais.

Observou-se que a maioria das publicações classificadas como científicas nessa pesquisa não conseguem manter a periodicidade definida, o que é grave, tendo-se em vista que uma das características fundamentais da publicação periódica está vinculada à definição e à regularidade dessa periodicidade.

Além da periodicidade irregular, a maioria dos periódicos científicos apresenta números acumulados. Isso vem comprovar a dificuldade que os editores têm em manter a publicação dentro de uma periodicidade desejável. Fatores administrativos e financeiros e a falta de trabalhos para publicar são os maiores responsáveis por esses atrasos e dificuldades. A regularidade na edição é o ponto de estrangulamento da maioria dos periódicos científicos, indicador seguro das dificuldades enfrentadas pelos editores.

As instruções aos autores têm funções importantes no fomento da qualidade dos artigos publicados, pois ajudam a norteá-los sobre os critérios pelos quais os artigos serão julgados e sobre os aspectos formais que os trabalhos deverão apre- sentar. As instruções aos autores espelham a qualidade desejada pelo corpo editorial. Portanto, esse item é importante, pois evidencia os objetivos da revista, propugnados pelo corpo editorial, por exemplo, publicar artigos inéditos, com referências bibliográficas.

As instruções aos autores estão presentes na maioria dos periódicos analisados (53\%). Entretanto, neste trabalho procurou-se distinguir as instruções que apresentavam menção às normas para referências bibliográficas, por tratar-se de aspecto intimamente ligado à normalização, além do fato de a bibliografia constituir grande contribuição para aqueles que consultam os artigos. Esse tipo de instrução ressalta a preocupação com a difusão do saber por parte do corpo editorial. A menção às normas ou exemplos de referências bibliográficas foi o critério utilizado para distinguir instruções aos autores completas de sucintas.

As referências bibliográficas são outro aspecto crítico dos periódicos, pois apenas $31 \%$ as exigem e mencionam normalização nas instruções aos autores. Entretanto, nas instruções aos autores mais detalhadas é quase unânime a menção à elaboração da bibliografia de acordo com a NBR 6023 da ABNT.

O sumário do fascículo esteve presente em todas as revistas, em alguns casos sofrendo alterações ao longo dos anos, como incluir ou retirar o nome dos autores dos artigos, apresentar o conteúdo dividido em seções e colocar a numeração das páginas naqueles que não tinham essa informação.

Uma função importante do sumário diz respeito a possibilitar a indexação de periódicos em indexes, o que é mais difícil para os periódicos que não o apresentam, enquanto aqueles que publicam sumário em outra língua abrem o leque de opções para indexação. Não foram encontrados sumários em outra língua.

A maioria dos periódicos não exige e não inclui resumos dos artigos de forma sistemática $(86,67 \%)$, o que evidencia pouca preocupação com a indexação. Isso é um aspecto negativo, principalmente pelo fato de restringir a informação que poderia ser disseminada em determinados indexes impressos e bases de dados eletrônicas. Em três dos quinze periódicos analisados, todos os artigos apresentam resumos (20\%); um deles apresenta 
também abstract e outro, palavras-chave. Isso facilitaria a indexação desses periódicos em determinados tipos de indexadores.

Quanto à identificação dos autores, os periódicos têm evoluído; entretanto, percebe-se que não há muita uniformidade, que alguns autores são apresentados com titulação, ocupação, instituição de origem, enquanto outros, só com parte dessas informações. Via de regra, independentemente do tipo de autoria, se individual ou coletiva, nos quinze periódicos em andamento, os autores estão identificados, ainda que nem sempre com muitos detalhes.

\section{ANÁLISE DOS ARTIGOS PUBLICADOS NOS PERIÓDICOS NACIONAIS DE CONTABILIDADE}

Foram analisados a autoria e o tema de 874 artigos publicados, durante o período de 1990 a 1999, nos periódicos Revista Brasileira de Conta- bilidade - R.B.C., Revista do Conselho Regional de Contabilidade do Rio Grande do Sul - RCRC/RS, Caderno de Estudos/Fipecafi - C.E., Enfoque Reflexão Contábil - ERC e Contabilidade Vista e Revista - CVR.

A Revista Brasileira de Contabilidade e a Revista do Conselho Regional de Contabilidade do Rio Grande do Sul, além de serem as mais antigas das cinco, são periódicos de necessária referência na área contábil produzidos fora das estruturas universitárias. Em virtude da abrangência dos seus interesses editoriais, esses periódicos publicam, além de artigos, depoimentos, entrevistas, pontos de vista, notas, informações, resenhas. Foram analisados somente os artigos científicos.

O Caderno de Estudos e as revistas Enfoque Reflexão Contábil e Contabilidade Vista e Revista são publicações representativas de uma tendência crescente das universidades, que é reunir e publicar a produção científica no âmbito da instituição, e encontram-se entre as mais antigas.

\section{QUADRO 2}

QUANTIDADE DE ARTIGOS ANALISADOS

\begin{tabular}{|l|c|c|c|}
\hline \multicolumn{1}{|c|}{ PERIÓdIcos } & $\begin{array}{c}\text { Total de } \\
\text { Artigos }\end{array}$ & $\begin{array}{c}\text { Qtde.de Fascículos } \\
\text { Pesquisados }\end{array}$ & $\begin{array}{c}\text { Média de Artigos } \\
\text { por Fascículo }\end{array}$ \\
\hline Caderno de Estudos/Fipecafi & 93 & 21 & 4 \\
\hline Contabilidade Vista e Revista & 114 & 17 & 7 \\
\hline Enfoque Reflexão Contábil & 96 & 18 & 5 \\
\hline Revista Brasileira de Contabilidade & 314 & 49 & 6 \\
\hline Revista do Cons. Reg. de Contab. do Rio Grande do Sul & 257 & 40 & 6 \\
\hline TOTAL & 874 & 145 & - \\
\hline
\end{tabular}

\section{Análise dos Artigos Quanto aos Temas Abordados}

Verificou-se, inicialmente, a distribuição dos artigos por área temática. Os seguintes temas tiveram maior afluência de artigos: $1^{\circ}$ ) Contabilidade Gerencial, $2^{\circ}$ ) Contabilidade Financeira, $3^{\circ}$ ) Teoria da Contabilidade, $4^{\circ}$ ) Educação e Pesquisa Contábil, 5ํ) Contabilidade de Custos, 6º Exercício Profissional, $7^{\circ}$ ) Contabilidade Pública, Orçamento Público e Finanças Públicas e $8^{\circ}$ ) Contabilidade Internacional. Os demais temas apresentaram pequeno percentual de artigos publicados.
Segundo MAHER (2000), nos anos 80 , nos mais conceituados periódicos estrangeiros, principalmente norte-americanos, cresceu a quantidade de trabalhos sobre Contabilidade Gerencial.

Conforme os resultados obtidos na análise temática dos artigos dos cinco periódicos em questão, constatou-se que no Brasil, na década de 90, ocorreu o que foi observado nos Estados Unidos, na década de 80 , pelo autor citado.

Já no Brasil, desde seu reconhecimento como disciplina do ensino formal até o início da década de 80 , a Contabilidade desenvolveu-se à luz da Contabilidade Financeira e da legislação societária e fis- 
cal. Na década de 90, consolidou-se a descentralização do enfoque das pesquisas contábeis da área quase que estritamente financeira para outras áreas, evidenciando a abertura de opções de áreas de atuação e pesquisa nessa ciência.

As áreas temáticas privilegiadas com maior percentual de trabalhos, em especial a Contabilidade Gerencial, a Teoria da Contabilidade, a Educação e Pesquisa Contábil e a Contabilidade de Custos, apontam para a transformação no ensino da Ciência Contábil e na formação profissional dos contadores, no Brasil, no período recente, como alguns dos fatores que influíram na atual distribuição dos temas dos estudos contábeis.

O tema Teoria da Contabilidade é um exemplo típico de área de pesquisa cujo interesse foi despertado pela participação dos autores dos artigos em cursos de pós-graduação, uma vez que, enquanto disciplina de graduação, sua inserção nos currículos é muito recente. Essa assertiva é reforçada pelo fato de a maioria dos autores ter feito pós-graduação, seja especialização, mestrado ou doutorado.

Isso denota a mudança de foco da preocupação dos autores, que passaram a estudar e escrever mais sobre assuntos que oferecem um diferencial para outros estudiosos e usuários das informações contábeis, como é o caso dos assuntos relacionados ao tema Contabilidade Gerencial, bem de acordo com o atual momento de globalização, em que as informações para tomada de decisões gerenciais assumem importância cada vez maior.

Não se entenda com isso que a Contabilidade Financeira tenha perdido a importância, entretanto é evidente que outros temas ganharam espaço entre os assuntos de interesse da comunidade científica contábil, o que pode ser resultado do maior amadurecimento científico proporcionado pelos cursos de pós-graduação realizados e da necessidade de respostas criada pelas transformações socioeconômico-culturais vividas no país.

É notório que alguns temas agregam maior número de artigos e outros possuem baixíssima produção publicada, o que indica uma clara predominância de alguns interesses temáticos. Verificouse a ocorrência dessa predominância de interesses temáticos, por periódico.

Nos periódicos Caderno de Estudos/Fipecafi, Contabilidade Vista e Revista e Enfoque Reflexão
Contábil, o tema Educação e Pesquisa Contábil está entre os cinco mais freqüentes, o que é bastante coerente, tendo em vista a natureza da instituição produtora desses periódicos, que reforça a preocupação com o ensino e a formação dos profissionais egressos das universidades.

Os artigos com assuntos relacionados ao tema Exercício Profissional são mais constantes na RBC e na RCRC/RS, o que também é bastante coerente, tendo em vista a natureza da instituição produtora destes periódicos.

A RCRC/RS, além de outros autores, conta com a colaboração de quatro, que a cada número contribuem com um artigo sobre sua especialidade, o que resultou numa ordenação diferente dos temas mais freqüentes nos demais periódicos, que são os seguintes: $1^{\circ}$ ) Contabilidade de Custos e $2^{\circ}$ ) Contabilidade Pública, Orçamento Público e Finanças Públicas e Contabilidade Gerencial e $3^{\circ}$ ) Teoria da Contabilidade. Em todos os outros periódicos, no período 90/99, o tema mais freqüente é Contabilidade Gerencial.

Um desafio para o milênio que se inicia é a discussão mais freqüente de assuntos relacionados à Contabilidade Internacional, como globalização de mercados e harmonização das práticas e normas contábeis, principalmente em função do Mercosul, uma vez que o assunto é atual e de grande interesse para a comunidade científica.

Em suma, pode-se dizer que os temas mais abordados nos periódicos evidenciam uma mudança no paradigma contábil, realçando a importância da Contabilidade Gerencial e das pesquisas sobre esse tema, bem como o interesse dos pesquisadores sobre os assuntos a ele relacionados.

\section{Análise dos Artigos Quanto à Autoria}

A análise dos artigos quanto à autoria está centrada em três pontos: a filiação institucional, a ocupação e a titulação dos autores.

De acordo com a localização das instituições às quais se vinculam os autores dos artigos, foi possível verificar de onde se originaram as contribuições para a produção científica contábil, por região do país.

Predominam os autores vinculados a instituições pertencentes à região Sudeste $(49,14 \%)$. O maior 
percentual, em seguida deste, refere-se a autores vinculados a instituições pertencentes à região Sul $(41,08 \%)$.

O maior desenvolvimento socioeconômico-cultural vivido por essas duas regiões do país tem influência no fato de a maioria dos cursos de pós-graduação em contabilidade se encontrarem nelas, e no fato de quatro dos cinco periódicos componentes da amostra se originarem delas, pois, segundo IUDíCIBUS (1987), no entendimento da evolução do estado-da-arte da contabilidade, é importante reconhecer que raramente esta se adianta muito em relação ao grau de desenvolvimento econômico, institucional e social das sociedades de cada época.

Portanto, a análise dos dados obtidos sobre a origem institucional dos autores conduz à conclusão de que o maior avanço das regiões Sul e Sudeste tem um impacto direto na formação e na produção científica contábil do país.

Os artigos publicados nos periódicos componentes da amostra, oriundos de autores vinculados a instituições das regiões Norte, Nordeste e CentroOeste, são escassos (0,07\%, 6,55\% e 2,52\%).

A precariedade das condições para a formação de cientistas contábeis nessas regiões explica, em parte, esse fato. Os cursos de pós-graduação stricto sensu existentes nas regiões Norte, Nordeste e Centro-Oeste são recentes.

Os cursos de especialização nessas regiões estão em menor percentual do que os existentes nas regiões Sul e Sudeste; por outro lado, a qualidade desses cursos, em todo o país, tem sido indicada na literatura como de qualidade duvidosa para a formação de indivíduos para a realização de pesquisas. Tudo isso contribui para que os trabalhos oriundos de indivíduos vinculados a instituições das regiões Norte, Nordeste e Centro-Oeste estejam em menor proporção.

$\mathrm{Na}$ origem institucional dos autores dos artigos dos periódicos Caderno de Estudos/Fipecafi, Contabilidade Vista e Revista e Enfoque Reflexão Contábil, que, devido ao fato de serem produzidos por instituições de ensino ou centros de pesquisa em Contabilidade, foram classificados nessa pesquisa como periódicos científicos, preponderam autores vinculados à instituição produtora dos periódicos.

Essa predominância de autores ligados à instituição produtora do periódico não é privilégio da
Ciência Contábil, mas ocorre em outras ciências, tanto no Brasil, quanto em outros países; citem-se, por exemplo, observações semelhantes a este respeito, feitas por DAVID \& GONÇALVES (1982), em pesquisa sobre periódicos brasileiros de economia.

Pode-se dizer que, como existiam na Ciência Contábil, praticamente, só dois periódicos até o final da década de 80, e, como na década de 90 começou a haver uma maior cobrança pela publicação da produção científica, em virtude da avaliação quantitativa das ciências, o caminho seguido pelas Instituições de Ensino Superior foi o de criarem os seus próprios periódicos, para viabilizar a divulgação das suas pesquisas.

Essa assertiva pode ser reforçada pelo fato de a maioria dos periódicos correntes de contabilidade estarem vinculados a Instituições de Ensino Superior, que mantêm cursos de pós-graduação (especialização, mestrado e doutorado), e pelo fato de que tanto esses cursos quanto esses tipos de instituições são avaliados, em parte, pela quantidade de pesquisas produzidas e publicadas.

$\mathrm{Na}$ análise da origem institucional dos autores dos artigos publicados nos periódicos Revista Brasileira de Contabilidade e Revista do Conselho Regional de Contabilidade do Rio Grande do Sul, classificados nessa pesquisa como periódicos genéricos, por serem veículos próprios de associações profissionais, pesou o fato de que, ainda que alguns autores possam ser considerados colaboradores dessas instituições, por ocuparem cargos como conselheiros ou presidentes, não são profissionais a elas vinculados. Entretanto, ressalte-se o fato de que somente são publicados artigos de profissionais registrados no órgão produtor da revista.

Observou-se que a RBC publica artigos de autores de várias regiões do país, sendo esse um aspecto bastante favorável para esse periódico, pois significa que o mesmo tem uma forte penetração na comunidade nacional.

A maioria dos autores dos artigos publicados na $\mathrm{RCRC/RS}$ originam-se do mesmo Estado ou, ainda que de outro Estado, da mesma região do seu órgão produtor. Esse resultado implica uma interação mais restrita com a comunidade científica regional, ou seja, presta-se mais à divulgação de trabalhos produzidos nesse âmbito.

Com isso, tanto a RCRC/RS quanto os três pe- 
riódicos científicos recaem no conceito de house organs, que mais se prestam para veicular a produção da comunidade na qual se inserem, aspecto negativo para esses periódicos, que, no caso da $\mathrm{RCRC/RS}$ e do Caderno de Estudos/Fipecafi, é amenizado pela existência de conselho editorial com membros de várias instituições do país e possuidores de titulação e credibilidade que assegurem imparcialidade e competência no julgamento dos trabalhos.

Entretanto, é oportuno frisar que se está analisando a origem dos autores dos artigos publicados e não se os periódicos estão fechados para autores não-ligados à comunidade científica na qual a sua instituição produtora do periódico se insere.

Pode-se considerar a concentração de profissionais qualificados uma explicação razoável para o fato de esses periódicos publicarem principalmente a produção científica gerada nas comunidades nas quais se inserem.

Entretanto, a pouca presença de trabalhos de autores de fora da comunidade produtora do periódico pode ser conseqüência da falta de trabalhos para publicar, o que se pode considerar um reflexo do próprio estágio de desenvolvimento da Ciência Contábil e de seus cientistas.

Considerando-se que, no Brasil, são escassos os Centros ou Institutos de Pesquisa e Sociedades Científicas na área contábil, é nas universidades que se realiza a maioria das pesquisas nessa ciência.

Além disso, ainda é nas universidades e, mais especificamente, na carreira docente, que se encontram mecanismos de incentivo à atividade de pesquisa como redução de carga horária em sala de aula, ascensão funcional, acesso a recursos financeiros e materiais, complementação salarial, além de outros incentivos, como o prestígio na comunidade científica.

Os resultados obtidos acerca da ocupação dos autores corroboram essas assertivas, uma vez que a maioria dos autores dos artigos publicados nos periódicos pesquisados são professores de graduação ou de pós-graduação (77\%).

O fato de os periódicos serem utilizados principalmente por docentes revela a preocupação e o compromisso com a realização e a publicação de pesquisas, por parte desses indivíduos.

$\mathrm{Na}$ análise da titulação, constatou-se que pre- ponderam os autores que são apenas graduados $(45,95 \%)$. Entretanto, se considerado o somatório do percentual de doutores, mestres e especialistas $(54,05 \%)$, esse valor chega a ser maior que o de graduados.

Convém ressaltar que, tendo em vista o reduzido número de cursos de mestrado e doutorado em contabilidade existentes no país, o percentual de autores mestres e doutores é grande $(48,90 \%)$, evidenciando que os cientistas contábeis têm se preocupado com a qualificação através da realização de cursos de mestrado e doutorado e conseqüente obtenção de títulos acadêmicos, assim como têm contribuído significativamente com a produção científica contábil do país.

Analisou-se, também, se a autoria dos artigos indicava a realização de pesquisas coletivas ou individuais, ao longo do período 1990/1999. Constatou-se que os cientistas envolvidos com produção científica contábil, nesses dez anos, não modificaram uma tendência, já observada em estudos de outras áreas do conhecimento, segundo CASTRO \& SCHWARTZMAN (1986), de predomínio de investigações individuais, conduzidas por autores isolados, atendendo aos seus interesses individuais.

\section{CONCLUSÕES E SUGESTÕES}

A pesquisa levantou aspectos muito importantes sobre a maneira como é conduzida no Brasil a atividade da publicação periódica na Ciência Contábil. A descrição e a análise das características formais dos periódicos revelou:

- que houve um crescimento acelerado no número de periódicos na década de 90 , coincidindo com a grande ênfase dada nesse período à avaliação quantitativa da produção científica na avaliação das IFES e da CAPES, e com o surgimento da maioria dos cursos de pós-graduação lato sensu e de novos cursos de mestrado em contabilidade;

- que essas publicações originaram-se predominantemente nas regiões em que se concentram os cursos de pós-graduação em Contabilidade, voltados, principalmente, para preparar indivíduos para o exercício da docência e para a realização de pesquisa científicas; 
- que, nos periódicos nacionais de contabilidade, a apresentação das características reconhecidas, internacionalmente, como importantes, para atestarem sobre a qualidade dessas publicações e, conseqüentemente, dos artigos selecionados para publicação, ainda é incipiente.

A análise do conteúdo dos artigos revelou que os temas enfocados são de grande interesse para a comunidade contábil, sendo tratados também assuntos escassos na literatura nacional, o que reforça a importância dos periódicos e do seu conteúdo.

A análise dos artigos mostrou também que as universidades e os cursos de pós-graduação impulsionaram o desenvolvimento de pesquisas visando à reflexão sobre o impacto das transformações tecnológicas, organizacionais, socioeconômico-culturais nos assuntos relacionados à Ciência Contábil, bem como à solução dos problemas decorrentes dessas transformações, demonstrando um avanço da ciência e dos cientistas contábeis no país.

Finalmente, mostrou-se, com a análise da autoria dos artigos, que a origem institucional, a ocupação e a titulação dos autores são um reflexo do contexto da produção científica contábil do país, espelhando as condições para a realização de pesquisas, para a obtenção de formação para realizálas, e a influência da avaliação quantitativa na produção científica e na produção de periódicos.

Consultas ao site da CAPES, sobre a produção bibliográfica dos docentes e discentes dos programas de pós-graduação em Contabilidade, demonstram que se tem revelado, a esse respeito, uma tendência que evidencia uma migração de parte dessa produção para anais de eventos técnicos e científicos. Entretanto, essa tendência não diminui a importância do estudo dos periódicos nacionais de Contabilidade, enquanto um dos principais veículos de comunicação da produção científica contábil.

O presente estudo não realizou uma avaliação da qualidade dos periódicos nacionais de Contabili- dade, mas acredita-se que a análise seja útil, principalmente para facilitar o conhecimento de critérios e variáveis adequadas à avaliação dos periódicos e que a discussão do atual estado-da-arte dos periódicos nacionais de Contabilidade contribua para o seu aperfeiçoamento.

Sugere-se a sistematização e a disseminação das informações acerca das características formais dos periódicos, essenciais para os tornar mais eficazes no desempenho das suas funções e mais representativos para a comunidade.

Sugere-se a criação de um grupo de trabalho permanente, vinculado a órgão de classe ou IES, que se responsabilize por estudar alternativas para a melhoria da produção e a distribuição dos periódicos da área contábil.

Como a figura do editor é fundamental no gerenciamento dos periódicos, sugere-se a criação de uma associação de editores de periódicos de contabilidade no Brasil e a realização de reuniões freqüentes, anuais ou semestrais, entre os membros dessa associação e demais interessados, como ocorre em outras Ciências, neste e em outros países, formalizando a discussão dos problemas comuns aos periódicos e buscando a solução para essas questões.

As reuniões poderiam tomar espaço em eventos como o Congresso Brasileiro de Contabilidade, o Encontro da Associação Nacional de Pós-Graduação em Administração - ANPAD, à qual se vinculam também os cursos de mestrado e doutorado em Contabilidade, e o Congresso Brasileiro de Custos.

Sugere-se a criação de um catálogo de periódicos nacionais de contabilidade, por órgão de classe ou IES, em que sejam compilados os resumos dos artigos, por autores, por títulos, por periódicos, por palavras-chave e os índices dos fascículos, e que este seja divulgado nacionalmente e atualizado freqüentemente.

Sugere-se, finalmente, a realização de estudos complementares que possam contribuir para a melhoria da qualidade e da difusão da produção científica. 


\section{REFERÊNCIAS BIBLIOGRÁFICAS}

BENJAMIN, James J. e BRENNER, Vincent C. Perceptions of journal quality. The Accounting Review. April. 1974.

BORBA, J. Alonso \& FREZATTI, Fábio. Análise dos traços de tendência de uma amostra das revistas científicas da área de contabilidade publicadas na língua inglesa. Caderno de Estudos/Fipecafi. Departamento de Contabilidade e Atuária/FEA/USP. V.13. N. 24. Julho/Dezembro. 2000.

CASTRO, R. C. F., FERREIRA, M. C. G. \& VIDILI, A. L. Periódicos latino-americanos: avaliação das características formais e sua relação com a qualidade científica. Ciência da Informação, v. 25, N. 3, 1996.

CASTRO, Cláudio de Moura \& SCHWARTZMAN, Simon. $\mathrm{Da}$ arte de financiar e ser financiado. In Pesquisa universitária em questão. CASTRO, Cláudio de Moura \& SCHWARTZMAN, Simon.: Organizadores. Ed. Ícone, Ed. da Unicamp e CNPq. São Paulo. 1986.

DAVID, Maurício e GONÇALVES, Reinaldo. A produção acadêmica nas principais revistas de economia: balanço de uma década. Literatura Econômica, IV, 3 (maio-junho de 1982), 283-308.

FELIU, Vicente Ripoll \& GOMES, Josir Simeone. Investigacion en contabilidad de gestion: estudio brasileño/español. Revista Brasileira de Contabilidade. Ano XXVII. No. 112. Jul./Ago., 1998.

FELIU, Vicente M. Ripoll e PALANCA, Mercedes Barrachina. Desenvolvimento científico da contabilidade de gestão. Revista de Administração. São Paulo. V.35, no. 1, p.98-106, janeiro/março, 2000.

HOWARD, Thomas P. e NIKOLAI, Loren A. Attitude measurement and perceptions of accounting faculty publication outlets. The Accounting Review. Vol. LVIII, No. 4, October, 1983.

HULL, Rita P. e WRIGHT, Gail B. Faculty perceptions of journal quality: an update. Accounting Horizons, March, 1990.

IUDÍCIBUS, Sérgio de. Teoria da contabilidade. Atlas. São Paulo. 1987.

KRZYZANOWSKI, Rosaly Favero \& FERREIRA, Maria Cecília Gonzaga. Avaliação de periódicos científicos e técnicos brasileiros. Ciência da Informação. Brasília, v. 27. N. 2, p. 165 - 175, maio/ago./ 1998.

ORTEGA, Cristina, FÁVERO, Osmar \& GARCIA, Walter. Análise dos periódicos brasileiros de educação. Revista Brasileira de Estudos Pedagógicos, Brasília, v. 79 , n. 193, p. 161 - 195, set./dez. 1998.

PRATHER, Jenice e RUESCHHOFF, Norlin. An analysis of international accounting research in U.S. academic accounting journals, 1980 through 1993. Accounting Horizons. Vol. 10, No. 1. March 1996. p. 1- 17.

REY, Luís. Como redigir trabalhos científicos. Ed. Edgard Blücher Ltda. São Paulo. 1978.

RICCIO, Edson Luiz, SAKATA, Marici Cristine Gramacho e SEGURA, Liliane Cristina. Um estudo sobre a pesquisa em custos no Brasil. VI Congresso Brasileiro de Gestão Estratégica de Custos. São Paulo. 1999.

SCHWARTZMAN, Simon. A política brasileira de publicações científicas e técnicas: reflexões. Revista Brasileira de Tecnologia. 15 (3) : 25 - 32, maio/jun., 1984.

ZEFF, Stephen A. A study of academic research journals in accounting. Accounting Horizons. Vol. 10, No. 3. September 1996. pp. $158-177$. 


\begin{tabular}{|c|c|c|c|c|c|c|c|c|c|c|c|c|c|c|c|}
\hline 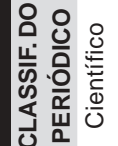 & 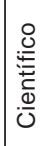 & 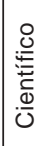 & 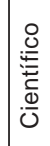 & 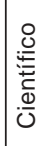 & 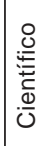 & 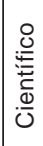 & 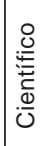 & 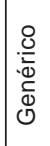 & 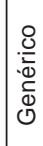 & 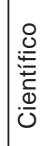 & $\stackrel{8}{=}$ & 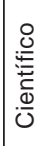 & 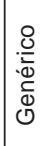 & 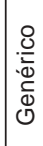 & 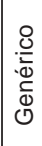 \\
\hline
\end{tabular}

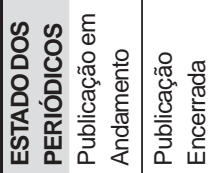

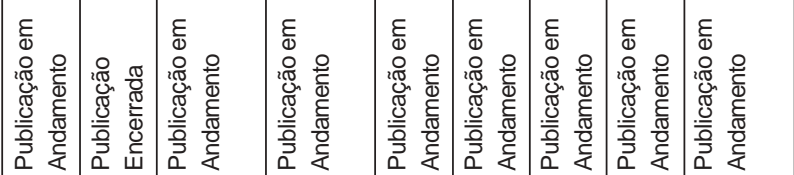

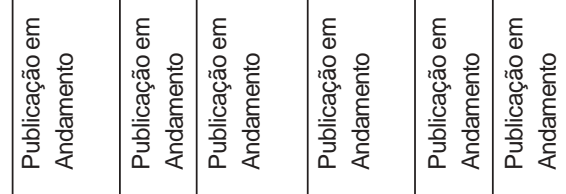

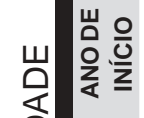

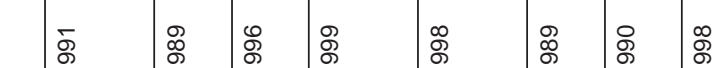

(n)

当

(n)

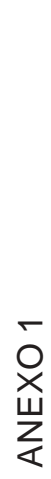

造

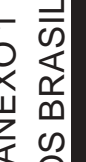

茴

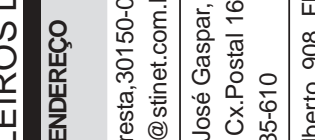

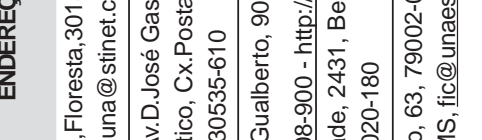

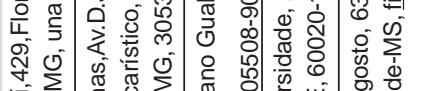

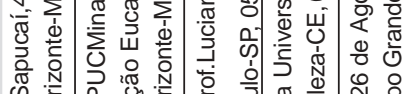

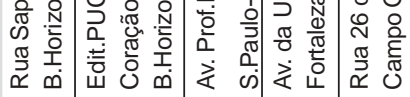

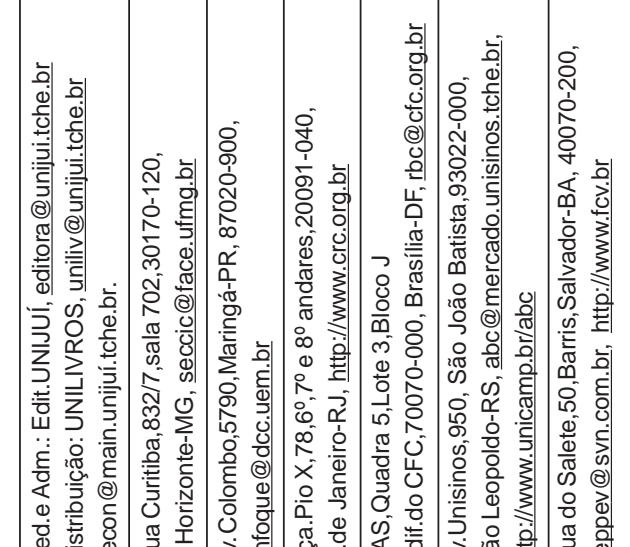

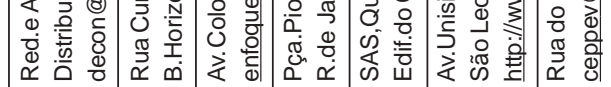

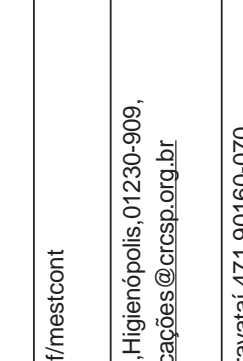

1.

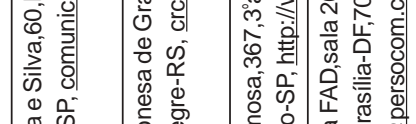

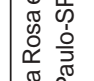

美

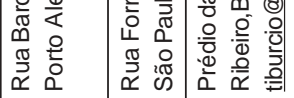

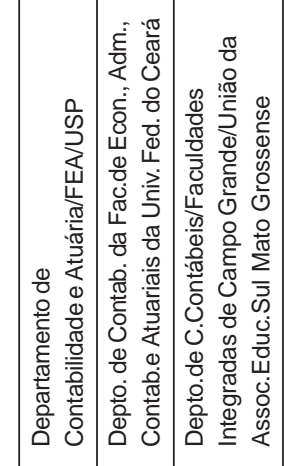

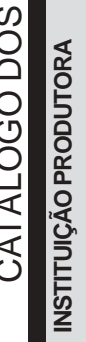

$\sum_{0}^{0} \sum_{0}^{0}$

$\stackrel{\circ}{\frac{2}{\pi}}$

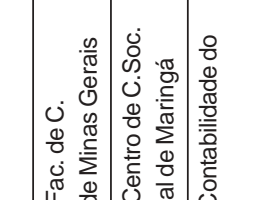

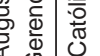

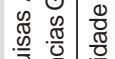

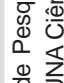

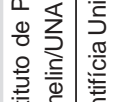

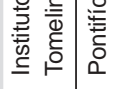

msos

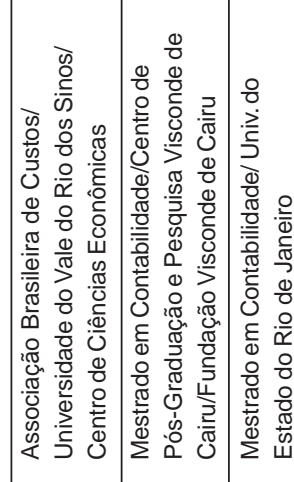

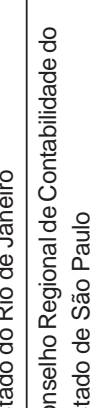

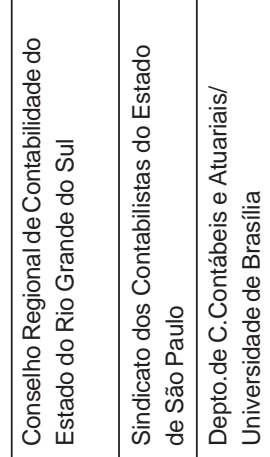
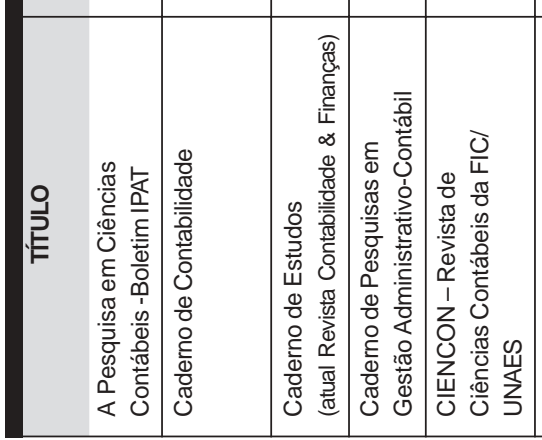

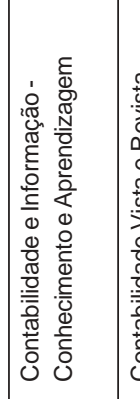

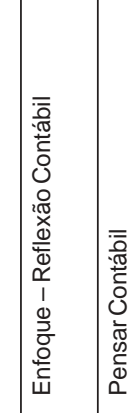
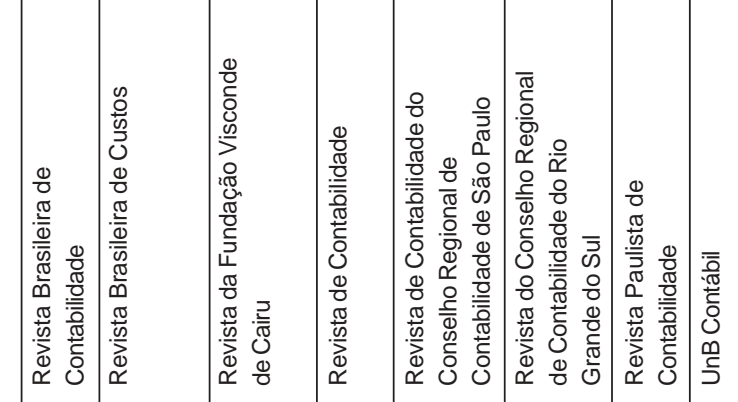


\section{ANEXO 2 \\ CLASSIFICAÇÃOTEMÁTICA E ASSUNTO}

\begin{tabular}{|c|l}
\hline 1 & $\begin{array}{l}\text { Contabilidade e Mercado de Capital - Influência das Demonstrações Contábeis no Mercado de Capitais e na } \\
\text { variação no preço das ações. }\end{array}$ \\
\hline 2 & $\begin{array}{l}\text { Educação e Pesquisa Contábil - currículos; métodos de ensino; metodologia de pesquisa; recursos materiais } \\
\text { utilizados; formação dos docentes; as dificuldades do ensino prático; aproveitamento de disciplinas; concurso vestibu- } \\
\text { lar para ciências contábeis; aspectos relativos à formação do contador como educação continuada; pós-graduação. }\end{array}$
\end{tabular}

3 Contabilidade para Empresas em Tipos Específicos de Atividades - aspectos contábeis específicos em entidades imobiliárias; cooperativas; agropecuárias.

4 Contabilidade para Tipos Específicos de Organizações - aspectos contábeis e fiscais referentes a pequenas e médias empresas; joint venture; sociedades em conta de participação; sociedades sem fins lucrativos não governamentais.

5 História da Contabilidade - surgimento, desenvolvimento e tendências da contabilidade, evolução do ensino formal da contabilidade e da literatura contábil, no Brasil e no restante do mundo.

6 Teoria da Contabilidade - epistemologia da contabilidade; princípios e normas contábeis; aspectos teóricos, conceituais e doutrinários relativos a ativo, passivo, receita, despesa, patrimônio, lucro, valor.

7 Auditoria Externa e Interna - prestação de serviços de auditoria, integração dos serviços de auditoria interna e externa; o planejamento do trabalho de auditoria e a avaliação dos riscos inerentes; relatórios de auditoria; controle de qualidade dos serviços de auditoria.

8 Contabilidade de Custos - métodos de custeio; a cientificidade da contabilidade de custos; a utilidade e validade do instrumental da contabilidade de custos; a contabilidade de custos no moderno ambiente empresarial; custos da qualidade.

9 Contabilidade Financeira - aspectos relativos à elaboração e evidenciação das Demonstrações Contábeis, envolvendo: normas contábeis e fiscais, ajustes de fim-de-exercício, inventário, equivalência patrimonial, consolidação, reavaliação de ativos, retificações do Balanço Patrimonial, provisionamentos, livros contábeis e fiscais, aspectos conceituais e práticos da correção monetária integral das demonstrações contábeis; reconhecimento da variação do poder aquisitivo; conversão das demonstrações contábeis para moeda estrangeira.

10 Perícia Contábil - avaliação dos fundos de comércio, fraudes, falências, concordatas.

11 Contabilidade Internacional - comparação das diferentes normas e princípios que norteiam a contabilidade nos diversos países do mundo; harmonização das normas e princípios contábeis dos países latino-americanos e do mundo; globalização da economia; mediação e arbitragem.

12 Contabilidade Gerencial - Análise de Custos, Orçamento Empresarial, Gestão Estratégica de Custos, Sistemas de Informações Gerenciais, Administração Financeira, Preço de Transferência, Avaliação de Desempenho, Padrões, Métodos Quantitativos Aplicados à Contabilidade; Custo de Oportunidade, Análise das Demonstrações Contábeis, Fixação do Preço de Venda, Controladoria.

13 Exercício Profissional - aspectos referentes ao exercício profissional, como mercado privativo de trabalho, fixação de honorários, contratação dos serviços, responsabilidades do contratado e contratante, sigilo, responsabilidades por perdas e danos causados a terceiros, contratação através de licitações; empresas prestadoras de serviços contábeis - a administração, o uso da informática e o gerenciamento dos custos; aspectos da ética profissional; exame de suficiência; organização sindical; responsabilidade pela edição de normas de contabilidade e auditoria.

14 Contabilidade Pública, Orçamento Público e Finanças Públicas - objetivos básicos; controle interno; controle do patrimônio público; enfoque gerencial na administração pública; estrutura organizacional e relatórios de órgãos públicos; reforma fiscal.

15 Contabilidade Social e Ambiental - Balanço Social; Contabilidade do Meio Ambiente; Contabilidade de Recursos Humanos.

16 Contabilidade Tributária - Planejamento Tributário; regras fiscais versus princípios e normas contábeis.

17 Outros - aspectos contábeis referentes a processos de privatização; cálculos atuariais; e outros assuntos não cobertos nos temas anteriores. 